\title{
IMPACT OF GREENHOUSE EFFECT GASES ON CLIMATIC CHANGES. MEASUREMENT INDICATORS AND FORECAST MODELS
}

\author{
Professor PhD Valentina Vasile, Senior Researcher I, Institute of National Economy, \\ Romanian Academy,email: ieconn@b.astral.ro \\ PhD Mariana Balan, senior researcher II, Institute for Economic Forecasting, \\ Romanian Academy, email: mariana_prognoza@yahoo.com
}

\begin{abstract}
The existence of a heavier layer of greenhouse effect gases at the level of the entire planet triggered significant climate changes. The paper intends to present the main environmental indicators elaborated by various specialised international bodies, and the models used by different governmental or non-governmental European bodies for studying the impact of greenhouse effect gas emissions on climatic changes or economic development. Also, a comparative analysis was made about the performance indicators obtained by means of differing models for forecasting greenhouse effect gas emissions by highlighting the information advantages/disadvantages in elaborating strategies and policies for limiting the negative effects.
\end{abstract}

Keywords: greenhouse effect gas emissions, impact, performance indicators, modelling

JEL Codes: C13, C22, Q43, Q53

Climatic changes have turned into a major challenge already at the end of the $20^{\text {th }}$ century. These are a direct or indirect result of human activities that trigger the change of the global atmosphere composition and are added to the natural variation of the climate observed for a comparable period of time ${ }^{1}$. The majority of the world scientific community is of the opinion that climatic changes can already be noticed which are determined by anthropogenic actions that generate glasshouse effect gas emissions. The effects of climatic changes are visible particularly in the increase of the average global temperature by $0,6 \pm 0,2^{\circ} \mathrm{C}$ from the moment in which the monitoring started (the year 1860). Other indicators highlighting the climatic changes are accelerated melt-down of icebergs during summer and an increase by 10 to $20 \mathrm{~cm}$ of the sea level in the $20^{\text {th }}$ century. Even if, at first sight, these phenomena might seem insignificant, their effects on daily life might become very severe. It is considered that climatic changes shall trigger a continued increase of the sea level which will endanger the coastal areas on the globe by erosion and flooding. They will also determine the intensification of extreme weather events and a change of precipitation patterns at global scale, leading to floods and draughts. Moreover, due to changes in weather conditions, changes of local ecosystems might occur and even the global cycles of water can be disturbed.

The climatic system is a common resource of mankind the stability of which may be affected by anthropogenic emissions of carbon dioxide and other greenhouse effect gasses ${ }^{2}$. The main objective of the United Nation Framework Convention on Climatic Changes is: "to achieve stabilization of greenhouse gas concentrations in the atmosphere at a level that would prevent dangerous anthropogenic interference with the climate system. Such level should be achieved

\footnotetext{
${ }^{1}$ The climate variability refers to the variations of the average state and other elements regarding climate on al time and room scales, above the individual weather events. The variability can be determined by some internal natural processes within the climatic system or by natural or anthropogenic natural variations.

2 1992, Earth Summitt from Rio de Janeiro, United Nations Convention on Climatic ChangesUNFCCC)
} 
within a time frame sufficient to allow ecosystems to adapt naturally to climate change, to ensure that food production is not threatened and to enable economic development to proceed in a sustainable manner." The Kyoto Protocol according to the principles governing sustainable development provides for flexible mechanisms for achieving the assumed targets so that the efforts of sinking greenhouse gas effects should be jointly realised at reasonable financial costs.

\section{Performance indicators in the field of environment}

The attempts to define and quantify the most significant performance indicators in the field of environment are numerous. Assisting companies in adopting the performance indicators, WBCSD $^{3}$ identified a series of selection principles of the indicators, among which:

- to be relevant for environmental changes, human health and quality of life;

- supporting the decisions taken about the way of improving performance;

- reorganising essential diversities within the business environment;

- supporting benchmarking and timely monitoring;

- to be clearly defined, measurable, transparent and verifiable;

- to be easily understandable and significant;

- to be based on the global evolution of production, and company services, focusing directly on the area of the management control;

- reconsidering some relevant issues for preventing "against flow" activities.

The performance indicators in the field of environment - KPI - may be grouped into two large categories: "lagging" and "leading" indicators. While the "lagging" indicators are in fact known as result indicators, for instance the emissions into the air and may be validated only in retrospect, by contrast the "leading" indicators are known as "process" indicators that measure the internal practices or efforts that are expected for improving performances. These two main categories of indicators are the ones used by companies for quantifying production impact on environment. Hence, it might be said that they can be considered as well as performance indicators on environment as well as indicators for environmental management (Table 1).

Environmental Indicators

\begin{tabular}{|c|c|}
\hline Environmental performance indicators & Environmental management indicators \\
\hline $\begin{array}{l}\text { Input indicators - materials } \\
\text { Consumption/output ratio } \\
\text { Packaging/output ratio } \\
\text { Packaging cost / output ratio } \\
\text { Reusable packaging ratio } \\
\text { Recyclable raw material ratio } \\
\end{array}$ & $\begin{array}{l}\text { Environmental costs } \\
\text { Environmental investment per year } \\
\text { Yearly operating cost of environmental protection per } \\
\text { year }\end{array}$ \\
\hline $\begin{array}{l}\text { Input indicators - energy } \\
\text { Energy cost ratio } \\
\text { Energy consumption/ total output ratio } \\
\text { Renewable energy ratio }\end{array}$ & $\begin{array}{l}\text { Training } \\
\text { Expenditure on environmental training per employee } \\
\text { Budget for environmental training }\end{array}$ \\
\hline $\begin{array}{l}\text { Output indicators - waste } \\
\text { Total waste to output ratio } \\
\text { Recycling waste ratio } \\
\text { Hazardous waste ratio } \\
\text { Reduction solid/liquid waste }\end{array}$ & $\begin{array}{l}\text { Purchasing indicators } \\
\text { Environmental assessment of suppliers conducted, (total } \\
\text { cost) }\end{array}$ \\
\hline $\begin{array}{l}\text { Output indicators - emissions } \\
\text { Amount of emissions to air / turnover } \\
\text { Costs of permits \& allowances }\end{array}$ & $\begin{array}{l}\text { Other } \\
\text { Environmental compliance improvement / costs of } \\
\text { compliance, impact of compliance on revenue }\end{array}$ \\
\hline
\end{tabular}

\footnotetext{
${ }^{3}$ World Business Council for Sustainable Development
} 
Source: Business Systems News for Finance and IT Professionals,

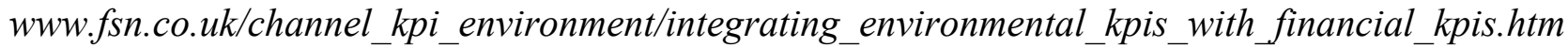

Sometimes, "normalisation" of KPI performance indicators with profit may be done in order to include the impact of inflation, exchange rate and changes in the marginal profit. Because this type of normalisation leads to obtaining some variables that influence company's profit, another form of normalisation is used frequently, that is the one realising the links between environment, for instance, emissions, waste or energy and materials used for production. These are useful particularly for proposed management operations, because they focus on the relationships that can be influenced by the individual management of the economic entity.

Companies using KPIs for the environment should take into account the current levels that can be measured by recording emissions at source, or by estimating the emission quantity using conversion factors.

The quantification manner of KPIs is selected so as to reflect the performances of the business environment in the context of achieving the proposed objectives. KPIs help the business environment in implementing strategies. The impact of environmental issues on the performance of the business environment is increasing and shall continue to grow. For instance, management quality for energy, natural resources or waste may affect the current performances. "Fractures" in future plans where environmental factors are not taken into account might lead to significant risks on long-term for the respective business environment. In this context, it is enough to remind the position of the Government of Great Britain who considers that the business environment shall need KPIs for identifying the connections between environment and financial performances.

The European Environment Agency supported the actions within Framework Programme 6 on environment and to these activities it associated actions, or issued strategies for supplying some sets of necessary indicators. From the multitude of environment indicators was realised a synthesis thereof, obtaining thus 11 groups of main indicators (Table 2).

Table no. 2.

\section{EEA environmental indicators}

\begin{tabular}{|c|c|c|}
\hline Issues & Current indicator & Proposals for ideal indicators \\
\hline \multicolumn{3}{|c|}{$6^{\text {th }}$ Action Programme on environment, topic: Climatic change } \\
\hline 1. Climatic change & $\begin{array}{l}\text { Emission aggregation for three } \\
\text { main types of greenhouse effect } \\
\text { gas emissions }\end{array}$ & $\begin{array}{l}\text { Aggregation of six types of greenhouse } \\
\text { effect gas emissions from the Kyoto } \\
\text { Protocol }\end{array}$ \\
\hline \multicolumn{3}{|c|}{$6^{\text {th }}$ Action Programme on environment, topic: Nature \& Biodiversity } \\
\hline 2. Nature \& Biodiversity & $\begin{array}{l}\text { Designation of "Special } \\
\text { Protection Area" }\end{array}$ & $\begin{array}{l}\text { Indices of biodiversity or preservation of } \\
\text { main species and habitats }\end{array}$ \\
\hline 3. Air quality: acidity & $\begin{array}{l}\text { Aggregation of emissions due to } \\
\text { acid substances }\end{array}$ & Same \\
\hline \multicolumn{3}{|c|}{$6^{\text {th }}$ Action Programme on environment, topic: Environment \& Human health } \\
\hline $\begin{array}{l}\text { 4. Air quality: summer- } \\
\text { smog }\end{array}$ & $\begin{array}{l}\text { Aggregation of emissions } \\
\text { leading to ozone layer shrinking }\end{array}$ & $\begin{array}{l}\text { same and the number of polluting days } \\
\text { exceeding standards }\end{array}$ \\
\hline 5. Air quality & $\begin{array}{l}\text { Number of surplus polluting } \\
\text { days }\end{array}$ & Indicators of urban air quality or indices \\
\hline 6. Water quality & $\begin{array}{l}\text { Phosphate and nitrate } \\
\text { concentration in large rivers }\end{array}$ & European indices of water condition \\
\hline 7. Chemicals & $\begin{array}{l}\text { Hazardous output of chemical } \\
\text { products }\end{array}$ & $\begin{array}{l}\text { Share of chemical products of hazardous } \\
\text { origin }\end{array}$ \\
\hline \multicolumn{3}{|c|}{$6^{\text {th }}$ Action Programme on environment, topic: Waste \& Resources } \\
\hline 8.Waste & $\begin{array}{l}\text { Random generation of waste } \\
\text { occupied lands }\end{array}$ & $\begin{array}{l}\text { Resources used in accordance with the } \\
\text { waste strategy }\end{array}$ \\
\hline 9. Used resources & Total internally used energy & Balance indicator for material \\
\hline
\end{tabular}




\begin{tabular}{|l|l|l|}
\hline 10. Water quantity & Result of total fresh water & Intensity of used water \\
\hline 11. Used land & $\begin{array}{l}\text { Land used by categories' } \\
\text { selection }\end{array}$ & Matrix of changing used lands. \\
\hline
\end{tabular}

Source: Science and Society Projects Synopsis 2002-2006/Science \&Society, Eur 22981, www.europa.eu

\section{Models used for estimating the quantity of greenhouse effect gas}

Modelling the links energy-environment-economy-trade is an important objective in the economic policy analyses. For instance, among the models used by various governmental or nongovernmental bodies from Great Britain for studying the impact of greenhouse effect gas on climatic changes or on economic development is counted also the BT model. Thus, for using this model are taken into account the determination of the quantity of carbon dioxide emissions (equivalent $\mathrm{CO}_{2}$ ) and the sources for emissions of this type were subjected to an inventory (figures $1-3)$.

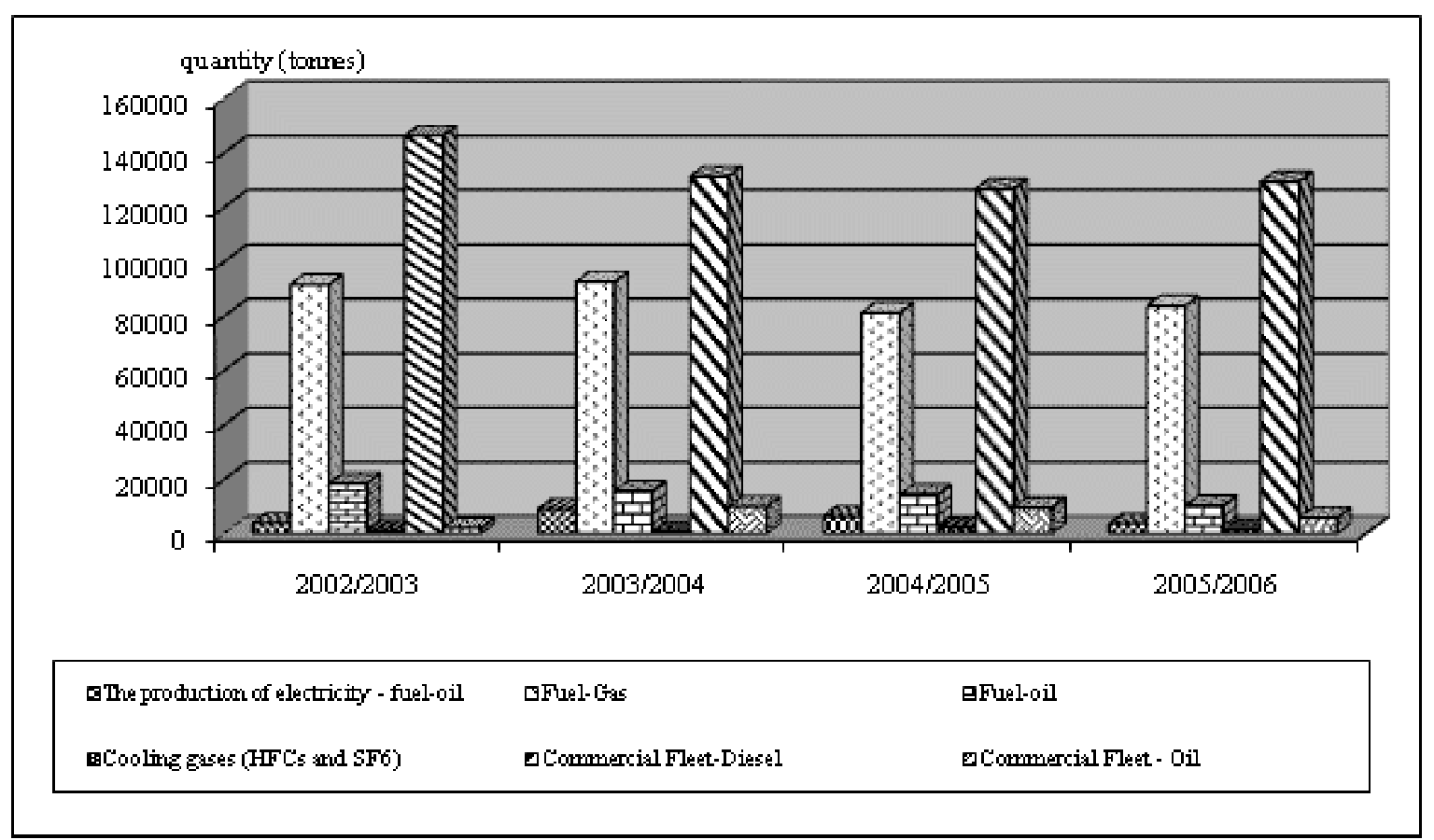

Fig. No. 1 The source of carbon dioxide emissions

Processing of authors,

Data source: Invoices, BT vehicle database, BT refrigerants database, BT expenses unit, BT travel management, DETR, AEAT NETCEN 


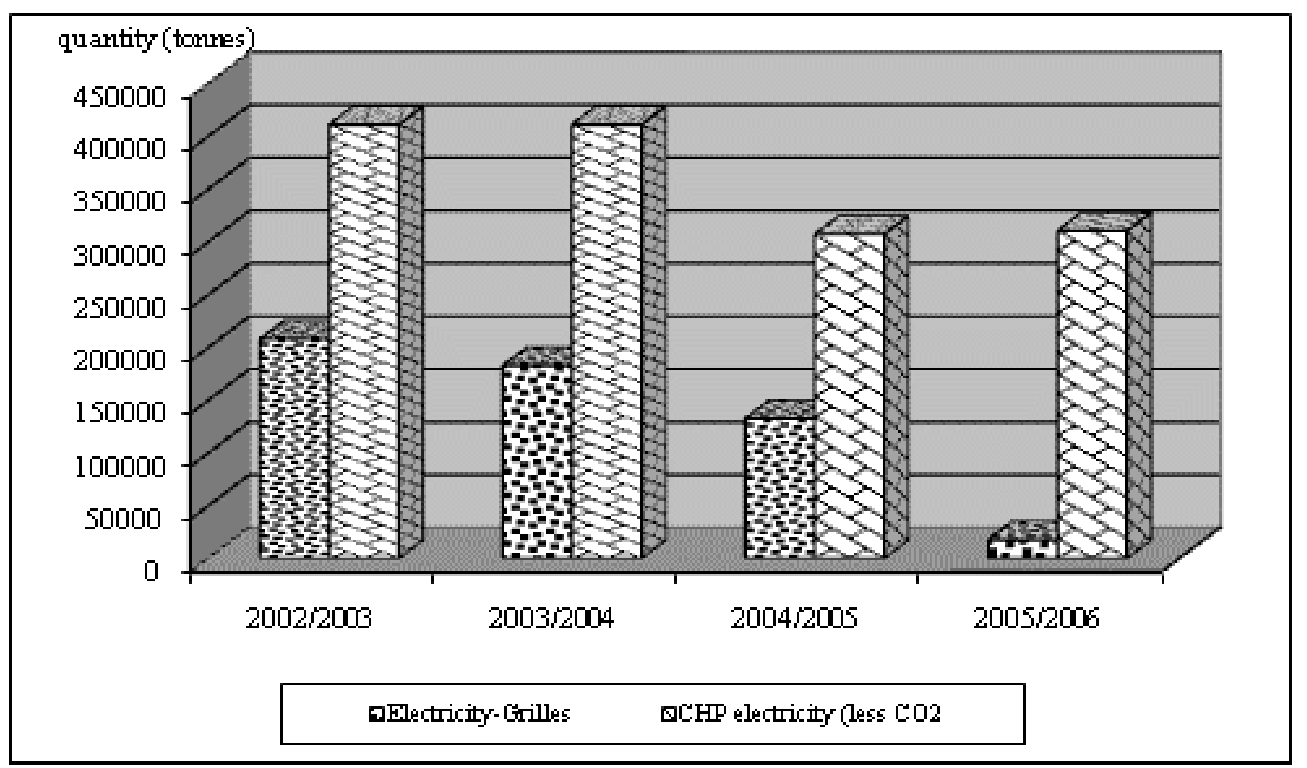

Fig.no 2 The source of carbon dioxide emissions

Processing of authors,

Data source: Invoices, BT vehicle database, BT refrigerants database, BT expenses unit, BT travel management, DETR, AEAT NETCEN

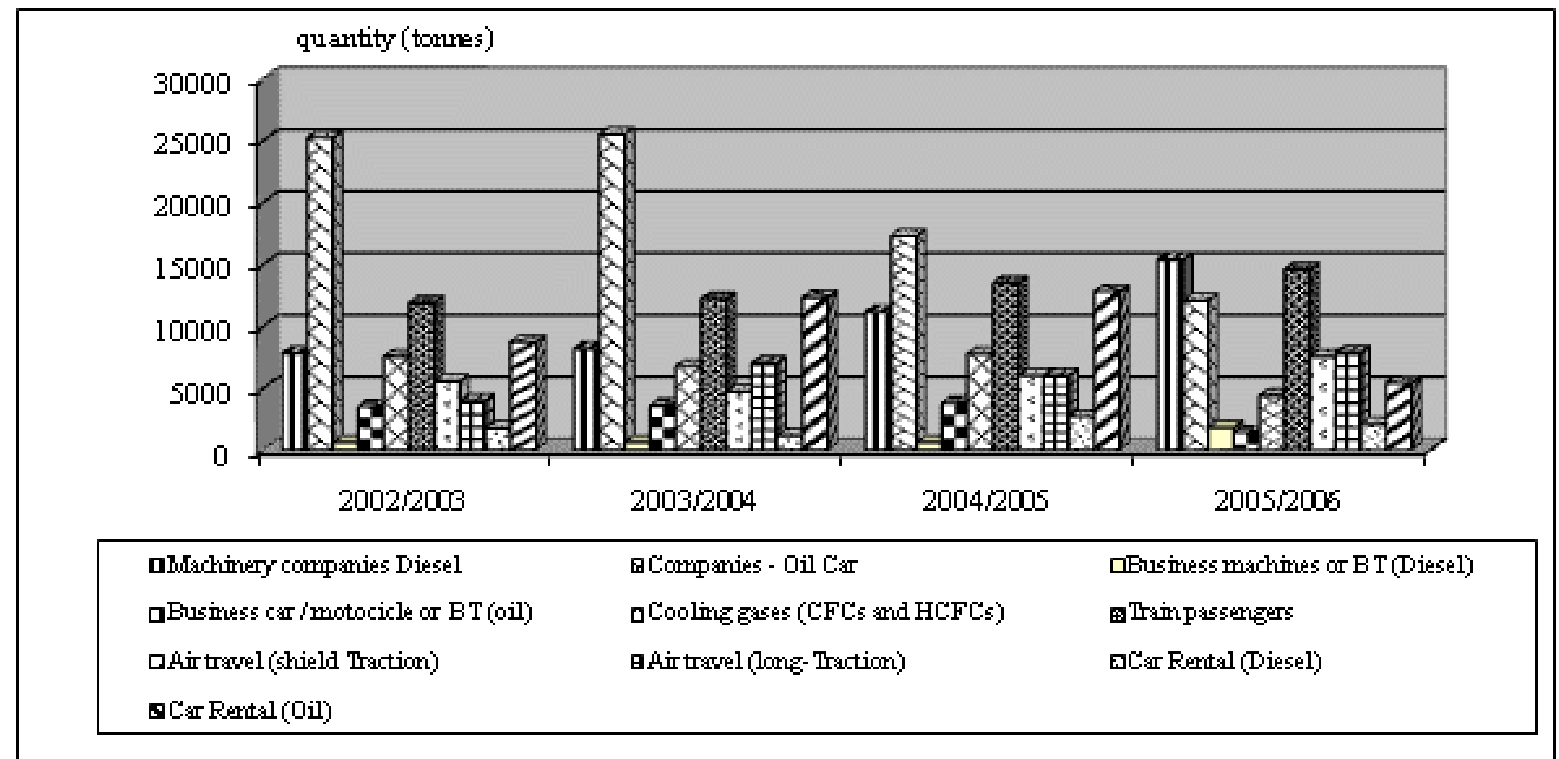

Fig.no. 3 The source of carbon dioxide emissions

Processing of authors,

Data source: Invoices, BT vehicle database, BT refrigerants database, BT expenses unit, BT travel management, DETR, AEAT NETCEN

Based on this model, depending on the source-sector of emissions was estimated the quantities of $\mathrm{CO}_{2}$ (figure 4). 


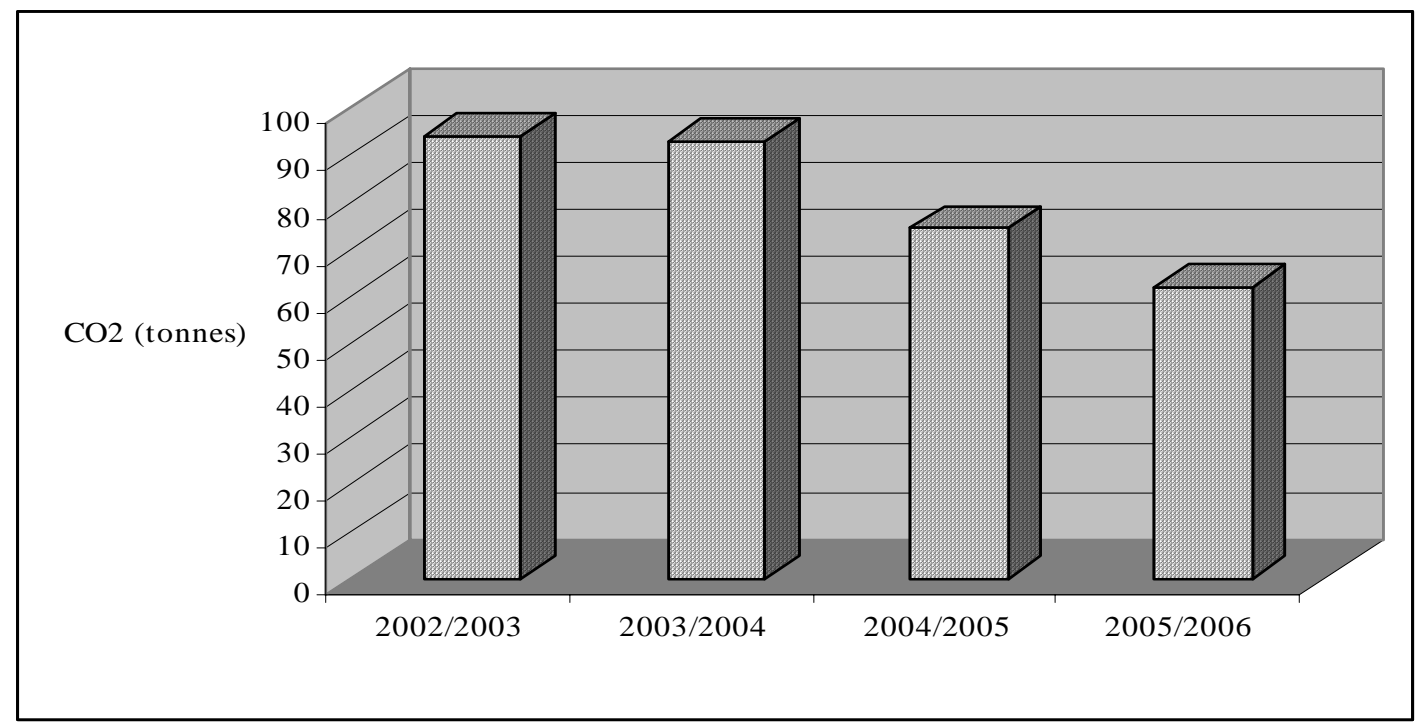

Fig.no 4. Estimating quantities of $\mathrm{CO}_{2}$, using the model BT

Processing of authors,

Data source: Invoices, BT vehicle database, BT refrigerants database, BT expenses unit, BT travel management, DETR, AEAT NETCEN

\subsection{EPPA Model for Europe: EPPA-EURO}

In the year 2003, the European Union determined the Emission Trading Scheme (ETS) for the period 2005-2007 (the Kyoto Conference, 2003). This Scheme was designed as an instrument to assist the transition of Member States to a system which could be in accordance with their commitments from the Kyoto Protocol and which covers the period 2008-2012. ETS takes into account the $\mathrm{CO}_{2}$ emissions of the large industrial entities, the Earth warming and the energyintensive sectors. It is a system which in itself is developed as allotments, rules and recordings which in some member countries have already been finalised already by the end of 2005 .

ETS analyses were realised by using of the EPPA model (the MIT Emissions Prediction and Policy Analysis model) the version for Europe being EPPA-EURO ${ }^{4}$. This model is used for realising forecasts of the greenhouse gas effect emissions generated by the world economy and the use of energy. Special forecasts are realised for analysing the influence of uncertainties, for instance, population growth and the economic activity, and the rate and direction of technological changes. EPPA allows its reformulation in the case of analysing the different variants of policies for emission control, allowing for estimations of the magnitude and distribution between nations of costs, but also for clarification of ways for which the changes are mediated by international trade.

The EPPA model is built based on a set of GTPA data which comprises a consistent representation of the energy markets in physical entities as details regarding regional outputs. EPPA uses in addition data on the gas emissions $\left(\mathrm{CO}_{2}, \mathrm{CH}_{4}, \mathrm{~N}_{2} \mathrm{O}, \mathrm{HFCs}\right.$, PFCs, and $\left.\mathrm{SF}_{6}\right)$ and of urban environment emissions $\left(\mathrm{SO}_{2}, \mathrm{NOx}, \mathrm{CO}, \mathrm{NH}_{3}, \mathrm{VOC}\right)$. In order to use the main version of the EPPA

\footnotetext{
${ }^{4}$ It is a recursive, dynamic, multi-regional model of general balance for the world economy. It is part of the Integrated Global Simulation Model (IGSM), which is used for forecasting the gas emission impact on climate and ecosystems. The EPPA model is used for analysing the processes generating relevant greenhouse effect gas emissions and for evaluating the consequences of policies proposed for controling these emissions. It is a global model, applied to the balance model of economic growth, international trade and greenhouse effect gas emissions $\left(\mathrm{CO}_{2}, \mathrm{CO}_{1} \mathrm{CH}_{4}, \mathrm{SO}_{2}, \mathrm{NOx}\right.$, $\mathrm{N}_{2} \mathrm{O}, \mathrm{NH}_{3}, \mathrm{CFCs}, \mathrm{PFCs}, \mathrm{HFCs}, \mathrm{SF}_{6}$ ) from various economic regions. The model includes such information on other components, for instance NMVOC.
} 
model, the GTAP data set was aggregated into 16 regions and 10 sectors. In addition, in the model were introduced the regional aggregations at European level for the version of the EPPA-EURO model (see Annex 1).

The engineering details are incorporated in the EPPA model for representing some possible demands of energy technologies. Gas industry from synthetic coal generates a perfect substitution for natural gas. Oil industry in argyle layers generates a perfect substitution for crude oil. Electricity generating technologies make a perfect substitution for electricity, save for solar and wind energies. In the EPPA model, the production and consumption sectors are represented by the substitution elasticity constant (SEC) of the production function (Cobb-Douglas or Leontief). The model is written in GAMS-MPSGE.

The EPPA-EURO model has certain particularities against the EPPA model. Thus, the TRAN sector is for which the EPPA model represents the sector of transports in a certain region, in the variant for Europe is not included. This comprises the sectors with large emissions. The sectors considered in EPPA comprising large installations are ELEC and EINT. In Table 3 are presented the percentage emissions of each country estimated in NAPs (National Allocation Plan) aggregated in EPPA regions as well as the percentages of gas emissions in the sectors EINT and ELEC for the year 2000. The analysis of the data from the table indicated that between the sectors considered in EPPA-EURO and the EINT and ELEC sectors from EPPA there is similitude. The small differences were corrected by percentage changes in the absolute covering determined by the NAP of each Member-State so that the percentage diminishment of emissions will be the same in the model EPPA-EURO and in NAP.

Table no. 3

\section{Percentage of national $\mathrm{CO}_{2}$ emissions covered by ETS and the EINT and ELEC sectors of the EPPA model}

\begin{tabular}{|l|c|c|c|c|c|c|c|c|c|c|c|c|}
\hline & REU & FIN & FRA & DEU & GBR & ITA & NLD & ESP & SWE & HUN & POL & XCE \\
\hline NAP & 53 & 59 & 29 & 58 & 46 & 61 & 54 & 40 & 30 & 52 & 68 & 65 \\
\hline $\begin{array}{l}\text { EPPA- } \\
\text { EURO }\end{array}$ & 46 & 63 & 32 & 52 & 45 & 47 & 42 & 47 & 34 & 59 & 69 & 72 \\
\hline
\end{tabular}

Source: National Allocation Plans and EPPA-EURO.

Among other approximations of the model, following could be enumerated:

- inclusion of all sectors eliminated the representation of small pollution sources;

- modelling the interactions with existing energy taxes;

- EPPA was applied for various periods of time (the initial model being applied yearly): for the period 2005-2007 was considered as representative the year 2005, and for the period 2008-2012, the representative year was considered 2008;

- usual businesses and forecasts are the determinant keys of the carbon price.

\section{Results obtained with the help of the EPPA-EURO model}

In order to evaluate a possible evolution of the carbon price (per ton of $\mathrm{CO}_{2}$ ) with the help of the EPPA-EURO model, three scenarios were considered depending on the various regimes of changing the price of carbon in EU countries. The first scenario illustrates the price variation in the case where carbon does not change between countries. The second scenario is close to the ETS plan and other European projection. In the third scenario "hot air" was eliminated from the countries remained in Eastern Europe (figure 5). 


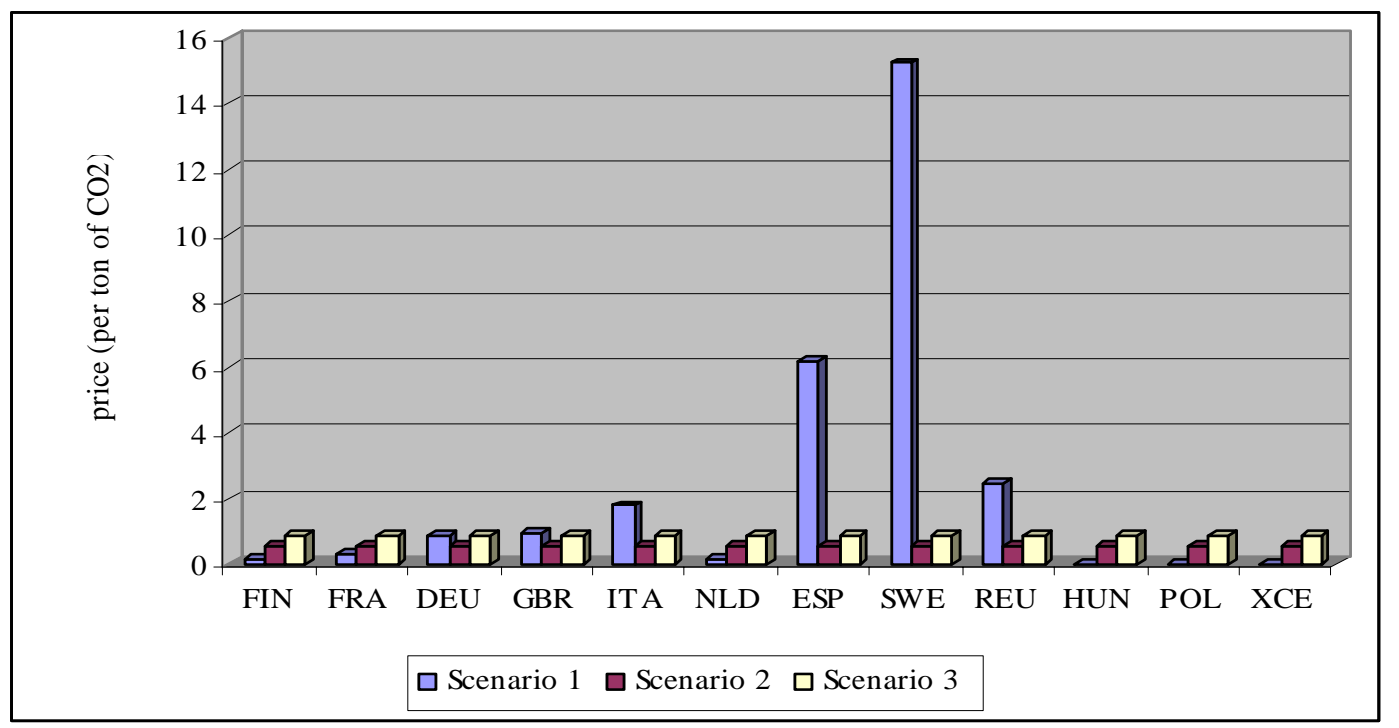

Fig. no 5. Carbon Price (per ton $\mathrm{CO}_{2}$ ) in different ETS scenarios.

Processing of authors,

Data source: MIT Joint Program on the Science and Policy of Global Change, An Analysis of the European Emission Trading Scheme, by John M. Reilly and Sergey Paltsev, Report No. 127, October 2005, www. globalchange.mit.edu

For explaining the unnatural high evolutions of the prices, in the model were introduced a series of theories and factors:

- the price increases for energy (oil and gas) due to a change of the coal used in the energy generating sector with high emissions of carbon;

- recent experiences have highlighted the potential effects of the climate changes (drought and very high temperatures) on the hydro and nuclear necessary. The drought reduces the hydro capacity and high temperatures lead to dysfunctions of nuclear plants;

- expectations on the future evolution of changes in the volume of high emissions after the year 2005 up to 2007. Financial allotments for the period 2008-2012 could be a way. France and Poland take into account the financial limits for the Kyoto period, but it is not yet clear whether financings will be also considered by the European Commission;

- the EPPA model might represent deviations very easy. The model does not represent with accuracy the details in market intentions and does not include transaction costs;

- current market prices of carbon do not show the interaction between demand and supply: confusions, speculations, incomplete recordings, false information, market manipulations, etc.

In the standard variant of EPPA simulations, the price of fuels is endogenously determined, but the model has the capability of considering this variable also exogenously. In order to express the impact of fuel price on carbon price, in this model variant the fuel price variable was considered exogenous.

The differences between the results of the simulation and reality are based on two important considerations:

- The high prices of fuels and the diminishment of the hydro and nuclear capacities were not anticipated as a shock, even though the EPPA model provides good outcomes with which companies could occasionally have time in such situations for adjustments. As long as EPPA is not a perfect forecasting model, the values of the substitution elasticity in the model reflect estimates on long term.

- The year 2005 it was appreciated as representative for the entire period 2005-2007 which determined the taking into account of its conditions for the entire period analysed. 
It should be emphasised that, under the conditions in which sinking financings are diminished, then complications might be expected which in the subsequent periods might lead to very high prices of carbon. In general, the EPPA-EURO model does not consider financings in the Kyoto period, but two Member States have included provisory financing.

Another hypothesis of this model version is the one where companies could consider that future diminishments should be based on the current emissions level from 2005 to 2007. Hence, the supposition is made that the diminishments in the period 2008-2012 could be considered as $20 \%$ under the values from the period 2005-2007. Starting from this hypothesis, an analysis could be made about the implication of this fact on the costs of over 1000 companies. Also, the model does not explain the implications of the fact that the period 2008-2012 covers five years, whereas the period 2005-2007 only three years, and that the effects on the emission diminishment might delay in the period starting with 2012 .

Another critical value in financing and in the computations on allocations as well, depends on the future price of carbon. Therefore, in the EPPA-EURO model was built a scenario where the various situations could be comprised that ETS should develop in the Kyoto period 2008-2012. In Table 4 are presented the scenarios considered in relationship with the carbon prices on the Kyoto period. Hence, in the fourth scenario the current sectors of the EPPA-EURO model were maintained and the "emissions quantity" unchanged for the period 2008-2012. This fact presupposes that other sectors of the economy shall diminish their emissions proportionally with the Kyoto target.

In the fifth scenario, the EPPA-EURO model was extended to all sectors and all EU regions. This scenario does not allow for crediting from outside EU.

The sixth scenario extends the study of emission changes on EU, Russia, Canada and Japan, by considering the emissions market in which they operate.

In the seventh scenario all gas emissions with greenhouse effect.

Scenarios for 2008-2012 and ETS Carbon Price (per ton CO2)

\begin{tabular}{|l|l|c|}
\hline Description & Carbon Price \\
\hline Scenario 4 & $\begin{array}{l}\text { ETS extended with unchanged quantity targets in the ETS } \\
\text { sectors to 2008-2012, and other sectors are capped to meet } \\
\text { Kyoto targets. }\end{array}$ & 13.47 \\
\hline Scenario 5 & $\begin{array}{l}\text { Kyoto target with trade among all sectors and across EU. } \\
\text { Emission trade in CO2 only }\end{array}$ & 32.32 \\
\hline Scenario 6 & $\begin{array}{l}\text { Kyoto target with trade among all sectors and across EU, } \\
\text { Canada, Japan, and Russia. Emission trade in CO2 only }\end{array}$ & 6.28 \\
\hline Scenario 7 & $\begin{array}{l}\text { Kyoto target with trade among all sectors and across EU, } \\
\text { Canada, Japan, and Russia. Emission trade in all GHGs }\end{array}$ & 0.70 \\
\hline
\end{tabular}

Source: MIT Joint Program on the Science and Policy of Global Change, An Analysis of the European Emission Trading Scheme, by John M. Reilly and Sergey Paltsev, Report No. 127, October 2005, www. globalchange.mit.edu

With respect to EPPA parameters for uncertainties of cost diminishment, it was highlighted the fact that if we consider the actual diminishment as only $1 \%$ under the reference one, then the choice of parameters influencing costs within the mode would be insufficient for generating the carbon price as compared with the one observed in the current ETS markets. Using the European variant of the EPPA-model and realising an analysis of uncertainty, the Monte Carlo method was used where the substitution elasticity between the energy input and non-energy were subjected to uncertainty and the results were compared with the ones obtained in the scenario without these assumptions. It was considered that in such a situation, where the share of the cumulated capital was varied. The effect of the substitution elasticity variation changed the average price by almost $5 \%$ 
and the maximum price by almost $10 \%$. The marginal effect of the accumulation was low in the maximum price, of approximately $7 \%$ and higher in the average price, of almost $15 \%$.

\subsection{The MEGABARE model for Europe}

The economic activity is strongly influenced also by the carbon dioxide emissions. One of the frequently used models is the MEGBARE 5 model, a model based on the general balance models and it has the capacity to describe the impact of some changes of the policies in the field of gas emissions sinking on a large number of economic variables. These include: price of consumption goods and the production input, the sectorial and regional outputs, investment and trade flows, national incomes and expenditures at the level of the countries. Within this model, population growth and capital accumulation are endogenous variables, which is in contrast to statistical models. The intermodal nature of the model is important for analysing the climatic change policies. The equations of the model describe production, consumption, and trade and investments representative for the producers and consumers from 30 regions and 41 categorised sectors. The data basis is used for simulating the impact of various emissions in 18 regions and 16 types of products. This aggregation allows for the study of the connection between consumer industries of fossil fuel and energy-intensive sectors, but also for the study of the marked changes in greenhouse effect gas emissions.

An important feature of this model is the "technology bundle", the access to modelling substitution possibilities of the fuel - electricity can be generated from coal, gas, nuclear, hydro or by renewing technologies.

In the model, industries combine production factors and intermediary inputs for generating a single product. The substitution is allowed between labour and capital. The assumption is made that land, capital and labour may be substituted in agreement with the SEC technology (substitution elasticity constant) which presupposes that the rate to which these three main factors can be substituted remains stable. Substitution elasticity between labour and capital is assumed as lower in the coal sector, reflecting thus the difficulties of actual substitution.

MEGABARE assumes that labour force is perfectly flexible between regions, thus the wage realises the balance on the labour market. Even though the labour demand is determined in simulations as endogenous, the magnitude of the changes in labour demand is determined by macroeconomic projections (hence exogenous).

MEGABARE simulations consider the following assumptions on the economic environment:

- the labour force supply and population are endogenously determined by a demographic model and are linked to economic variables (in particular incomes) by birth and mortality rates. The net migration rate is assumed as constant;

- the population growth and age structure are important determinants for each region with respect to the labour force demand and savings level;

- the capital is mobile at international level, it is assumed that savings shall finance always investments in the region of origin before investments abroad;

- the return rates are equalised over sectors within a particular region;

- the return rates over regions are assumed as possibly equal, allowing for some imperfections in the international capital market;

\footnotetext{
5 MEGABARE is an instrument for examining the climate change of policies, contains detailed information on the quantity of carbon dioxide emissions reasulting from fosile fuels in various economic activities. This model incorporates the fact that various fossil fuels have differing quantities of carbon dioxide emissions. As result, the projection of the emissions level for a region is given periodically as a function combining the type and quantity of fosile fuels used in the respective region in the period considered.
} 
- the unemployment rate in the regions is assumed as remaining constant by wage adjustments;

- all prices in the model are determined relatively to the global price of saving - the global price of saving being called cash;

- nuclear and hydro energy are assumed as restricted in the case of reference because the physical potential and the political one as well restrict their expansion. Other renewable energies are not subjected to restrictions.

\section{Policies simulation}

The close targets for achieving gas emission sinking proposed by the European Union and by a number of other countries, require that each country shall diminish own emissions with a given percentage related to the reference year 1990. Yet, this comes in contrast to the targets proposed by the economies of other countries and by the circumstances of trade that could take into account the quantities of emissions and under these conditions objective diminishments could be initiated.

For studying the policies of sinking gas emissions were elaborated two scenarios:

- A less stringent scenario: in which countries such as Australia, New Zealand, United States of America, Canada, Japan, the European Union (15) and the EFTA countries (Group A in the structure model) which determine their carbon dioxide emissions from fossil fuel at the level of the year 1990 up to the year 2010. It is based on a ten years delay in achieving the commitment contained in Article 4.2 of the Framework Convention on Climatic Changes - the diminishment of gas emissions from the level of the year 1990 up to the year 2010.

- A more stringent scenario: in which the mentioned countries determine their carbon dioxide emissions from fossil fuel up to 15 percents starting from the levels of the year 1990 up to 2010. It represents a consistent policy proposed by the Group of 77 and China at the international negotiations on the topic of climate change from Bonn (October 1997). The developed countries do not require a strict diminishment of their emissions in this scenario. This assumption is based on the need that after the Bonn negotiations the developed countries were not required to make a new commitment. This presupposes that in achieving gas emissions the governments adopt policy instruments that impose the possible diminishment of costs in their countries. In MEGBARE, the modelling of the costs' size to emissions diminishment implies imposing some taxes on the carbon dioxide emissions in each period and for each emission restriction enforced. The taxes lead to increasing the costs associated with the activities from carbon dioxide emissions and encourage the spread of resources in emission-less intensive activities.

Carbon taxes are representative for a large category of economic instruments that could be used by governments in diminishing emissions. In the context of the model simulations', the carbon taxes associated with the realisation of a corresponding level of emissions' diminishment may be also interpreted as unit price of the norm of national emissions changes. In more general terms, the carbon taxes could be interpreted as the marginal cost on economy associated with the minimum cost policy or a set of policies assigned for achieving a general level of emissions.

\section{Carbon leakages and structural changes}

The less stringent scenario implies a diminishment of emissions of about 20 percents up to the year 2010 (Table 5). The less stringent scenario assumes an emissions' sinking by 32.1 percents up to 2010 as compared with the case of the reference level. At the same time, the carbon dioxide emissions from countries outside the analysed group are forecasted to increase up to $2.7 \%$, respectively $4.5 \%$ up to 2010 in the less or more stringent scenario relative to the case of reference. This phenomenon is known under the name of "carbon leakage". "Carbon leakage" is partially compensated by the diminishment of emissions in countries included in group A by increasing the emissions in countries in group B. 
Table no. 5

$\mathrm{CO}_{2}$ emission changes at the level of year 2010 due to emission sinking in countries from Group A (\% of reference level)

\begin{tabular}{|l|c|c|}
\hline & Less stringent scenario & More stringent scenario \\
\hline Group A & -20.1 & -32.1 \\
\hline Group B & 2.7 & 4.5 \\
\hline Global & -9.3 & -14.8 \\
\hline
\end{tabular}

Group A: Australia, noua Zeelenadă, Statele Unite ale Americii, Canada, Japonia, Uniunea Europeană (15) şi țările EFTA

Group B: Republic of Korea, China, Taiwan-China, Indonesia, Rest of the Asia, India, Mexico, Brazil, Rest of America, Rest of th World

Source: MEGABARE projections, MIT Joint Program on the Science and Policy of Global Change, Carbon Emissions and The Kyoto Commitment in the European Union, by Laurent L. Viguier, Mustafa H. Babiker and John M. Reilly, Report No. 70, February 2001, www. globalchange.mit.edu

In the simulation of the MEGBARE simulations, the countries from Group A impose policies of diminishing the fossil fuels used for emissions sinking. These policies increase the production costs in industries using intensively fossil fuels, for instance iron and steel production and the non-ferrous metals' production. This leads to countries in Group B obtaining competitive advantages in the sectors using fossil fuels. As reaction, a partial change of the emissions in industries that are intensive consumers of fossil fuels from the countries in Group A to the ones in Group B.

The changes in total $\mathrm{CO}_{2}$ emissions previously presented are associated with global changes in the use of fossil fuels. The changes forecasted for the world consumption of coal, oil and natural gas are presented in Table 6.

Table no. 6

\section{Changes of primary energies used at the level of the year 2010 due to emission sinking in} countries from Group $A(\%$ of reference level)

\begin{tabular}{|l|c|c|}
\hline & Less stringent scenario & More stringent scenario \\
\hline Coal & -28.9 & -41.2 \\
\hline Oil & -3.3 & -5.3 \\
\hline Gas & -9.8 & -21.5 \\
\hline
\end{tabular}

Source: MEGABARE projections, MIT Joint Program on the Science and Policy of Global Change, Carbon Emissions and The Kyoto Commitment in the European Union, by Laurent L. Viguier, Mustafa H. Babiker and John M. Reilly, Report No. 70, February 2001, www. globalchange.mit.edu

The total coal quantity required is forecasted to decrease to 28.9 percents, respectively $41.2 \%$ in the scenarios considered up to 2010 , relative to the case of reference. This diminishment of the coal used may be attributed to some wide coal substitutions in the electric energy generating industry. The world decline forecasted for the use of oil is smaller than for coal or natural gas, especially due to the fact that oil products are used particularly in the transports' sector, where the possible substitutions are mode limited than in the electric energy generating sector.

The low demand of coal for countries in Group A is forecasted to impact on countries in Group B (Table 7). The coal output for countries in group A is forecasted to decrease by $7.6 \%$, respectively $8.1 \%$ in the scenarios considered at the level of the year 2010 . 
Table no. 7

Changes in the coal output due to $\mathrm{CO}_{2}$ emissions' sinking(\% of reference level)

\begin{tabular}{|l|c|c|}
\hline & Less stringent scenario & More stringent scenario \\
\hline Group A & -43.4 & -61.7 \\
\hline Group B & -7.6 & -8.1 \\
\hline Global & -30.0 & -41.7 \\
\hline
\end{tabular}

Source: MEGABARE projections, MIT Joint Program on the Science and Policy of Global Change, Carbon Emissions and The Kyoto Commitment in the European Union, by Laurent L. Viguier, Mustafa H. Babiker and John M. Reilly, Report No. 70, February 2001, www. globalchange.mit.edu

In spite of a high internal demand of fossil fuels, the coal output of countries in Group B is forecasted by the model to decrease due to the significant diminishment of coal exports to countries in Group A. Even though exports comprise only $9 \%$ from the coal output of the countries in group B, their export to regions in Group A comprise 65\% from total exported coal (1992), resulting a decrease by $34.5 \%$ in the exports' of the countries in Group B. The coal output for the regions in Group A is forecasted to decrease more than the one of countries in Group B, because the diminishment of the internal demand for fossil fuels in the intensive sectors associated with the diminishment of the aggregated demand and fossil fuel substitutions is in accordance with the targets proposed for emission sinking.

\subsection{GTAP-E model}

Because the GTAP model in its standard form does not contain as an essential factor the substitution energy the version GTAP-E was elaborated, which incorporates data on the carbon emission from fossil fuels, becoming thus a study mechanism of the greenhouse effect gas emissions at international level. Hence, the model may highlight the energy-economy interdependencies, representing an attempt of bringing economic models closer to the ones used by engineers and experts in environmental protection for studying the effect of energy policies on environment.

\section{Exigencies for Romania in applying the Kyoto Protocol}

Romania has signed the United Nation Framework Convention on Climatic Changes which has as main objectives to determine the concentration of greenhouse effect gas emissions in the air, at a level that should prevent any anthropogenic disturbance of the climatic system. The implementation of the measures determined by the Kyoto Protocol ${ }^{6}$ for Romania, starting from the main objectives presupposes:

- compliance with the commitments of sinking greenhouse effect gas emissions by $8 \%$ as compared to the reference year 1989 for the period 2008-2012;

- adopting a set of market mechanisms, including transferable trading permits and common enforcement of provisions, in cooperation with other countries.

From the polluters regulated in the Kyoto Protocol, in Romania are counted the following greenhouse effect gas emissions: carbon dioxide, nitrogen and methane oxides, and in perspective also the other gas provided in protocol shall be counted (fluorite hydrocarbons, per sulphur fluorites and hexa-fluorites).

\footnotetext{
${ }^{6}$ By Law no. 3/2001, Romania ratified the Kyoto Protocol on the United Nations Framework Convention on Climatic Changes, being among the first countries to ratify this international document of particular importance for the issue of climatic changes.
} 
Carbon dioxide emissions in the year1989 was of $194.826 \mathrm{Gg}$ (considered the value of reference), and at the level of the year 1994 of $125.597 \mathrm{Gg}$. For the year 2010 the estimates consider three scenarios:

Table no. 8

Forecast of some greenhouse effect gas emissions ( $\mathrm{Gg} \mathrm{CO}$ equivalent/year)

\begin{tabular}{|l|r|r|r|}
\hline & $\mathbf{2 0 0 0}$ & $\mathbf{2 0 0 5}$ & $\mathbf{2 0 1 0}$ \\
\hline \multicolumn{4}{|c|}{ Reference scenario } \\
\hline Total emissions $\mathrm{CO}_{2}$ & 162334.8 & 187794.0 & 228535.7 \\
\hline Total emissions $\mathrm{CH}_{4}$ & 33531.0 & 36740.0 & 43125.0 \\
\hline Total emissions $\mathrm{N}_{2} \mathrm{O}$ & 8480.0 & 10240.0 & 12704.0 \\
\hline Total emissions & $\mathbf{2 0 4 3 4 5 . 8}$ & $\mathbf{2 3 4 7 7 4 . 0}$ & $\mathbf{2 8 4 3 6 4 . 7}$ \\
\hline \multicolumn{4}{|c|}{ Minimum scenario } \\
\hline Total emissions $\mathrm{CO}_{2}$ & 158445.9 & 178926.0 & 201447.5 \\
\hline Total emissions $\mathrm{CH}_{4}$ & 33445.0 & 33712.0 & 36368.0 \\
\hline Total emissions $\mathrm{N}_{2} \mathrm{O}$ & 81280.0 & 9024.0 & 10112.0 \\
\hline Total emissions & $\mathbf{2 0 0 0 1 8 . 9}$ & $\mathbf{2 2 1 6 6 2 . 0}$ & $\mathbf{2 4 7 9 2 7 . 5}$ \\
\hline \multicolumn{4}{|c|}{ Maximum scenario } \\
\hline Total emissions $\mathrm{CO}_{2}$ & 150807.9 & 156432.0 & 167655.5 \\
\hline Total emissions $\mathrm{CH}_{4}$ & 32879.0 & 32164.0 & 32227.0 \\
\hline Total emissions $\mathrm{N}_{2} \mathrm{O}$ & 7744.0 & 7904.0 & 8256.0 \\
\hline Total emissions & $\mathbf{1 9 1 4 3 0 . 9}$ & $\mathbf{1 9 6 5 0 0 . 0}$ & $\mathbf{2 0 9 1 3 8 . 5}$ \\
\hline
\end{tabular}

Source: Ecosystem International, Climate changes, www.ecosysteminternational.ro/schimbari_climatice

For achieving the objectives of the Kyoto Protocol, Romania should take a series of measures, from which the most important would $\mathrm{be}^{7}$ :

- the industry shall have to become more efficient from the viewpoint of energy consumption, switching from the use of fossil fuel rich in carbon (coal) to carbon poor fuels, or to alternative fuels;

- extractive to consumption energy industry must be restructured so as to become efficient and less polluting;

- transport must be oriented towards less polluting means and reduced consumption;

- constructions should be energy efficient and aim to use renewable energy sources;

- equipment and products should be ones with low energy consumption;

- forests shall be protected and even expanded.

In Romania the major polluting sources are still functioning, reaching critical levels with economic, social and ecologic impact. After 1999 the greenhouse effect gas emissions are decreasing not only due to the diminishment of the industrial activity but also due, particularly, to the implementation of emissions diminishment programs. Romania has a considerable potential for projects in the framework of joint implementation, and in accordance with the forecasts of the

7 Romania ratified the Kyoto Protocol by the law for ratifying the Kyoto Protocol to the United Nations Framework Convention on Climatic Changes adopted on 11 Dec. 1979, no. 3/2001 published in the Official Bulletin No. 80/16.02.2001. 
experts there should be possible to achieve, at least, a diminishment higher than $6 \%$ of the greenhouse effect gas emissions in the case of Romania's commitment of $8 \%$.

The national ceiling of emissions provided in the NAP for the year 2007 is of 84.2 million tons $\mathrm{CO}_{2}$ and the average yearly ceiling for the period 2008-2012 is of 97.5 million tons $\mathrm{CO}_{2}$. The National Allocation Plan provides for the period 2008-2012 that a percentage of 8\% from the total number of greenhouse effect gas emissions certificates shall represent the reserve for the new entries who make other investments or expand old capacities.

Annex no. 1

Countries, regions and sectors considered in the EPPA model

\begin{tabular}{|l|l|}
\hline Countries or regions & Sectors \\
\hline Annex $B$ & Non-Energy \\
\hline United States of America (USA) & Agriculture (AGRI) \\
\hline Canada (CAN) & Services (SERV) \\
\hline Japan (JPN) & Energy-intensive products (EINT) \\
\hline European Union $+{ }^{\text {a) }}$ (EUR) & Other industrial products (OTHR) \\
\hline Australia/New Zealand (ANZ) & Transport (TRAN) \\
\hline Former Soviet Union (FSU) & Energy \\
\hline Eastern Europe ${ }^{\text {b) }}$ (EET) & Coal (COAL) \\
\hline Non-Annex $B$ & Crude oil (OIL) \\
\hline India (IND) & Refined oil (ROIL) \\
\hline China (CHN) & Natural gas (GAS) \\
\hline Indonesia (IDZ) & Electricity: Fossil fuels (ELEC) \\
\hline High incomes from Eastern Asia ${ }^{\text {c) }}$ (ASI) & Electricity: Hydro (HYDR) \\
\hline Mexico(MEX) & Electricity: Nuclear (NUCL) \\
\hline Central \& Southern America (LAM) & Electricity: Solar and Wind (SOLW) \\
\hline Middle East (MES) & Electricity: Biomass (BIOM) \\
\hline Africa (AFR) & Electricity: Combined cycles- Natural gas (NGCC) \\
\hline Rest of the World'(ROW) & Electricity: NGCC with insulation (NGCCS) \\
\hline & $\begin{array}{l}\text { Electricity: Integrated gaseification with combined } \\
\text { and insulation cycles (IGCC) }\end{array}$ \\
\hline & Oil of argyle layers l(SYNO) \\
\hline & Synthetic gas (SYNG) \\
\hline Hlouseholds \\
\hline & Own transports (OTS) \\
\hline & Purchasing Demand - Transport (PTS) \\
\hline
\end{tabular}

Source: MIT Joint Program on the Science and Policy of Global Change, An Analysis of the European Emission Trading Scheme, by John M. Reilly and Sergey Paltsev, Report No. 127, October 2005, www. globalchange.mit.edu

a) EU-15 + Norway, Switzerland, Island

b) Hungary, Poland, Bulgaria, Czech Republic, Romania, Slovakia, Slovenia.

c) South Korea, Malaysia, Philippines, Singapore, Taiwan, Thailand.

d) All countries not included elsewhere: Turkey and especially Asian countries 


\section{EU regional aggregation in the EPPA-EURO model}

\begin{tabular}{|l|l|l|l|}
\hline Country & EPPA-EURO region & \multicolumn{1}{|c|}{ Country } & EPPA-EURO region \\
\hline Austria & REU & Latvia & REU \\
\hline Belgium & REU & Lithuania & REU \\
\hline Cyprus & REU & Luxemburg & REU \\
\hline Czech Republic & XCE & Malta & REU \\
\hline Denmark & REU & The Netherlands & NLD \\
\hline Estonia & REU & Poland & POL \\
\hline Finland & FIN & Portugal & REU \\
\hline France & FRA & Slovakia & XCE \\
\hline Germany & DEU & Slovenia & XCE \\
\hline Greece & REU & Spain & ESP \\
\hline Hungary & HUN & Sweden & SWE \\
\hline Ireland & REU & UK & GBR \\
\hline
\end{tabular}

Source: MIT Joint Program on the Science and Policy of Global Change, An Analysis of the European Emission Trading Scheme, by John M. Reilly and Sergey Paltsev, Report No. 127, October 2005, www. globalchange.mit.edu

\section{References:}

1. Brian S. Fisher, Stephen Brow, The economic impacts of uniform emission abatement, 'Countdown to Kyoto': The Consequences of the Mandatory Global Carbon Dioxide Emissions Reductions, Australian APEC Study Centre, Canberra, 19-21 August 1997;

2. Cain Polidano, The impact of climate change policies on employment in the coalmining industry, SAP 2.64/WP.115;

3. Clive Hamilton, John Quiggin, Economic Analysis of Greenhouse Policy, Discussion Paper Number 15, December 1997, ISSN 1322-5421;

4. Hom Pant, Global Trade and Environment Model (GTEM): A computable general equilibrium model of the global economy and environment, Australian Bureau of Agricultural and Resource Economics Canberra, 2002;

5. John M. Reilly, Sergey Paltsev, An Analysis of the European Emission Trading Scheme, MIT Joint Program on the Science and Policy of Global Change, Report No. 127, October 2005 ;

6. Joseph Fiksel, Key Performance Indicators, World Business Council for Sustainable Development, March 2002;

7. Lisa Segnestam, Environmental Performance Indicators, A Second Edition Note, Environmental Economics Series, Paper No. 71, October 1999;

8. Niki Leahy, Integrating Environmental KPIs with Financial KPIs, CSR Report 2006;

9. R.C. Hyman, J.M. Reilly, M.H. Babiker, A. De Masin and H.D. Jacob, Modeling Non-CO2 Greenhouse Gas Abatement, MIT Joint Program on the Science and Policy of Global Change, Report No. 94, December 2002;

10. Sonja Peterson, CGE Models and Their Application for Climate Policy Analysis, Kiel Institute for World Economics, Germany, Octombrie 2003;

11. *** Environmental Key Performance Indicators, Reporting Guidelines for UK Business, Department for Environment, Food and Rural Affairs, www.defra.gov.uk, 2006; 